\title{
Can quantitative diffusion-weighted MR imaging differentiate between different subtypes of benign and malignant solitary thyroid nodules?
}

\author{
Ehab Ali Abdelgawad ${ }^{1 *}$, Enas Ahmed AbdelGawad', Othman AbuElCebaa² and Ahmed M. Atiya²
}

\begin{abstract}
Background: Diffusion-weighted MR imaging (DWI) is sensitive to changes in the microstructural organization of tissue that may influence water diffusion. It has been utilized in various forms to evaluate head and neck tumors. The apparent diffusion coefficient (ADC) value is a quantitative parameter for distinguishing malignant from benign thyroid nodule. Determination of different pathologic types of the thyroid nodules is crucial for appropriate therapeutic approach. Our point was to assess the utility of apparent diffusion coefficient values in discriminating different subtypes of benign and malignant solitary thyroid nodules using diffusion MRI with pathological correlation.

Results: This prospective study included 73 patients who had thyroid nodules. The size of the investigated lesions ranged from 0.6 to $3 \mathrm{~cm}$. Most nodules were benign (79.45\%), and most of these benign nodules were adenomatous nodules. There was a significant difference in ADC values of benign and malignant thyroid nodules $(P 0.0001)$, with the mean $A D C$ value for the benign group $\left(1.7 \pm 0.12 \times 10^{-3}\right)$ higher than that for malignant nodule $(0.71 \pm 0.15 \times 10)$. The sensitivity, specificity, and accuracy of ADC in differentiating between benign and malignant thyroid nodules were 97.5, 94.4 , and $99.2 \%$, respectively. We noticed a significant overlap in the ADC value of pathological subtypes and upon reviewing the pathological results, we found insignificant differences in the ADC values of the various subtypes of malignant and benign nodules, with $P$ value ranging from 0.054 to 0.062 between different pathological subtypes. A significant difference was only noted between non-complicated cysts and solid nodules $P 0.0001$. In our series, an ADC value of $0.92 \times 10^{-3} \mathrm{~mm}^{2} / \mathrm{s}$ or less could be used as an indicator of malignancy, with a sensitivity of $97.5 \%$, a specificity of $94.4 \%$, and an accuracy of $99.2 \%$.
\end{abstract}

Conclusion: Diffusion MRI including ADC values are helpful in differentiation between benign and malignant thyroid nodules but not helpful in differentiating between different subtypes of benign and malignant nodules.

Keywords: MRI, Diffusion, Thyroid nodules

\section{Background}

Solitary thyroid nodule is a single swelling in an otherwise normal gland. It is usually a benign lesion [1]. Most of the nodules tend to have a benign nature, and the malignancy has been reported in less than $5 \%$ of the nodules [2].

The most frequently used methods for assessing thyroid nodules are clinical examination, ultrasound,

\footnotetext{
* Correspondence: abdelgawadehab77@gmail.com

'Department of Radiology, Faculty of Medicine, Minia University, Minia, Egypt Full list of author information is available at the end of the article
}

thyroid scintigraphy (SC), and fine-needle aspiration biopsy (FNAB). There is no single reliable criterion used to separate among benign and malignant nodules [3]. Color Doppler US findings are controversial in terms of malignant nodules [4-7]. SC gives information about thyroid gland functions [8], however, risks of exposure to radiation and the fact that not all functioning nodules on scintigraphy are benign are major limitations [9-11]. Using FNAB, non-conclusive results were observed in $13-30 \%$ of patients, and malignancy percentage in this group changes between 10 and 50\% [12-14]. 
Conventional MRI of the thyroid gland can give information about the location and size of thyroid lesions but still do not have the specificity for distinguishing benign from malignant nodules [15].

Routine diffusion-weighted MR imaging (DWI) can measure the mobility of water molecules diffusing in tissues which is impacted by biophysical characteristics such as cell density, membrane integrity, and microstructure [16-18]. Recently, DWI has been used in differentiating benign and malignant nodules in the thyroid gland [19]. Apparent diffusion coefficient (ADC) value is a quantitative parameter for distinguishing malignant from benign thyroid nodule [15].

Determination of different pathologic subtypes of the thyroid nodules is crucial for appropriate therapeutic approach. Our aim was to evaluate the utility of apparent diffusion coefficient values in separating different subtypes of benign and malignant solitary thyroid nodules.

\section{Methods \\ Patients}

This prospective study was approved by the ethical committee of our institution. During the period between October 2017 and February 2018, 73 patients (27 male, 46 female) with solitary thyroid nodules were referred from the surgical clinic for MRI examination. Their ages ranged from 22 to 62 years with mean age 36 years. The age of presentation was the same age of the patients at time of study. All patients had and ultrasound examination of their thyroid gland prior to referral for MRI examination. All the patients were planned to undergo FNAB. Small nodules less than $10 \mathrm{~mm}$ were excluded from the study.

\section{MRI protocol}

All MRI examinations were performed using 1.5-T MRI system (Achieva, Philips Medical Systems, Koninklijke Philips Electronics N.V) using a neck coil. The neck coil was placed so that the thyroid gland is located in the central part of the FOV in each patient. Conventional MRI examination included axial T1-weighted sequence (TR/TE, 450/10 ms), and axial and coronal spin-echo T2-weighted sequence $(5500 / 90 \mathrm{~ms})$ with a section thickness of $4 \mathrm{~mm}$, an intersection gap of $1 \mathrm{~mm}$, FOV of $20-25 \mathrm{~cm}$, and an acquisition matrix of $256 \times 224$.

Diffusion-weighted MR images were obtained by using a multisection single-shot echo-planar imaging sequence. Multiple axial scans of the neck were obtained to cover the thyroid gland. Imaging parameters included the following: (matrix size, $190 \times 190$; number of slices, 30; slice thickness, $4 \mathrm{~mm}$; interslice gap, $1 \mathrm{~mm}$; field of view, $50 \mathrm{~cm}^{2}$; number of signals averaged, 5 ; acquisition time, $2 \mathrm{~min}$ ). Diffusion gradients were applied in three orthogonal directions simultaneously. DWI was acquired with $b$ values of $50,400,800$, and $1000 \mathrm{~s} / \mathrm{mm}^{2}$.

The ADC maps were recreated with economically accessible programming. ADC values were extracted from ADC maps. Averaged ADCs were calculated from the ADC map in rounded ROIs drawn on the regions. ROI area was $1 \mathrm{~cm}^{2}$; however, it may vary according to the size of the nodule. ROI measurements were done in the noncystic periphery of the nodule in nodules with solid-cystic components. To minimize noise, all measurements were performed three times from the ADC map for each lesion. The mean ADC value of these measurements was calculated and was taken into final analysis.

\section{FNAB and pathological examination}

FNAB was done for all patients following MRI examinations. FNABs were done under US guidance.

\section{Statistical analysis}

The ADC values of thyroid nodules were compared with the pathology results. Statistical analysis was done by using SPSS program software package version 13 and analyzed by the same software. Results were given as mean \pm standard deviation (SD). The Mann-Whitney $U$ test was performed to compare the histopathologic and quantitative ADC measurements of benign and malignant thyroid nodules. The probability ( $P$ value) of less than 0.05 was considered statistically significant. Receiver operating characteristic (ROC) curve was constructed to determine a cutoff value for differentiating malignant from benign solitary thyroid nodules.

\section{Results}

This prospective study included 73 patients who had thyroid nodules detected by thyroid ultrasonography and underwent MRI.

Methodological quality was relatively high and acceptable for interpretation in all examined patients. The size of the investigated lesions measured on T1weighted images ranged from 0.6 to $3 \mathrm{~cm}$ (mean, 1.4

Table 1 Number of each pathological subtype, age of presentation, and diameter of thyroid nodules

\begin{tabular}{llll}
\hline Pathologic subtypes & No. & Mean age & $\begin{array}{l}\text { Diameter of the } \\
\text { nodule }(\mathrm{cm})\end{array}$ \\
\hline Benign nodules & 58 & & \\
Adenomatous nodule & 37 & 36 & $2.3 \pm 0.32$ \\
Follicular adenoma & 12 & 32 & $2.1 \pm 0.24$ \\
Cysts & 9 & 28 & $1.85 \pm 0.21$ \\
Malignant nodules & 15 & & $1.8 \pm 0.12$ \\
Papillary & 11 & 46 & $1.5 \pm 0.15$ \\
Follicular & 4 & 58 & \\
\hline
\end{tabular}


Table 2 Mean ADC values of benign and malignant nodules

\begin{tabular}{llll}
\hline Pathology & No. & Mean ADC values $\left(\mathrm{mm}^{2} / \mathrm{s}\right)$ & $P$ value \\
\hline Benign & $58(79.45 \%)$ & $1.7 \pm 0.12 \times 10^{-3}$ & 0.0001 \\
Malignant & $15(20.55 \%)$ & $0.71 \pm 0.15 \times 10^{-3}$ & \\
\hline
\end{tabular}

$\mathrm{cm})$. Most nodules were benign (79.45\%), and most of these benign nodules were adenomatous nodules (37 of 58). Table 1 illustrates the number of each pathological subtype, age of presentation and diameter of each lesion.

There was a significant difference in ADC values of benign and malignant thyroid nodules ( $P$ 0.0001), with the mean ADC value for the benign group (1.7 $\pm 0.12 \times 10^{-3}$ ) higher than that for malignant nodule $(0.71 \pm 0.15 \times 10)$ despite there was an overlap in the ADC values between benign and malignant lesions (Table 2).

The ADC value of the adenomatous nodules ranged from 1.3 to $1.9 \times 10^{3} \mathrm{~mm}^{2} / \mathrm{s}$. The ADC of follicular adenoma (Fig. 1) was $1.23-2 \times 10^{-3} \mathrm{~mm}^{2} / \mathrm{s}$, and 1.14-2.4 $\times 10^{-3} \mathrm{~mm}^{2} / \mathrm{s}$ for thyroid cysts. ADC value for follicular carcinoma was $0.61-1.24 \times 10^{-3} \mathrm{~mm}^{2} / \mathrm{s}$ (Fig. 2), and for papillary carcinoma, it was $0.72-1.32 \times 10^{-3} \mathrm{~mm}^{2} / \mathrm{s}$ (Fig. 3). The sensitivity, specificity, and accuracy of ADC in differentiating between benign and malignant thyroid nodules were $97.5,94.4$, and $99.2 \%$, respectively.

We noticed a significant overlap in the ADC value of pathological subtypes, and upon reviewing the pathological results, we found insignificant differences in the ADC values of the various subtypes of malignant and benign nodules, with $P$ value ranging from 0.054 to 0.062 between different pathological subtypes. A significant difference was only noted between non-complicated cysts and solid nodules $P$ 0.0001. Two complicated cysts showed a low ADC value (Table 3).

A receiver operator characteristic (ROC) curve was computed for the ADC values obtained from DWI scans using $b=400 \mathrm{~s} / \mathrm{mm}^{2}$. We determined a cutoff point from the ROC curve that would differentiate benign from malignant lesions. The area under the curve measured $98 \%$. In our series, an ADC value of $0.92 \times$ $10^{-3} \mathrm{~mm}^{2} / \mathrm{s}$ or less could be used as an indicator of malignancy, with a sensitivity of $97.5 \%$, a specificity of $94.4 \%$, and an accuracy of $99.2 \%$.

\section{Discussion}

Solitary thyroid nodule is a single swelling in an otherwise normal gland. It is usually a benign lesion [1]. Most of the nodules tend to have a benign nature and the malignancy has been reported in less than $5 \%$ of the nodules [2].

The most frequently used methods for assessing thyroid nodules are clinical examination, ultrasound, thyroid scintigraphy (SC), and fine-needle aspiration biopsy (FNAB). There is no single reliable criterion used to separate among benign and malignant nodules [3]. Color Doppler US findings are controversial in terms of malignant nodules [4-7]. SC gives information about thyroid gland functions [8], however, risks of exposure to radiation and the fact that not all functioning nodules on scintigraphy are benign are major limitations [9-11]. Using FNAB, non-conclusive results were observed in $13-30 \%$ of patients, and malignancy percentage in this group changes between 10 and 50\% [12-14].

Conventional MRI of the thyroid gland can give information about the location and size of thyroid lesions but still do not have the specificity for distinguishing benign from malignant nodules [15].

Routine diffusion-weighted MR imaging (DWI) can measure the mobility of water molecules diffusing in tissues which is impacted by biophysical characteristics such as cell density, membrane integrity, and microstructure [16-18]. Recently, DWI has been used in differentiating benign and malignant nodules in thyroid gland [19]. Apparent diffusion coefficient (ADC) value is a quantitative parameter for distinguishing malignant from benign thyroid nodule [15].

Reduced ADC values have been reported for most malignant tumors and are thought to be due to cellular membranes impeding the mobility of water protons $[19,20]$.

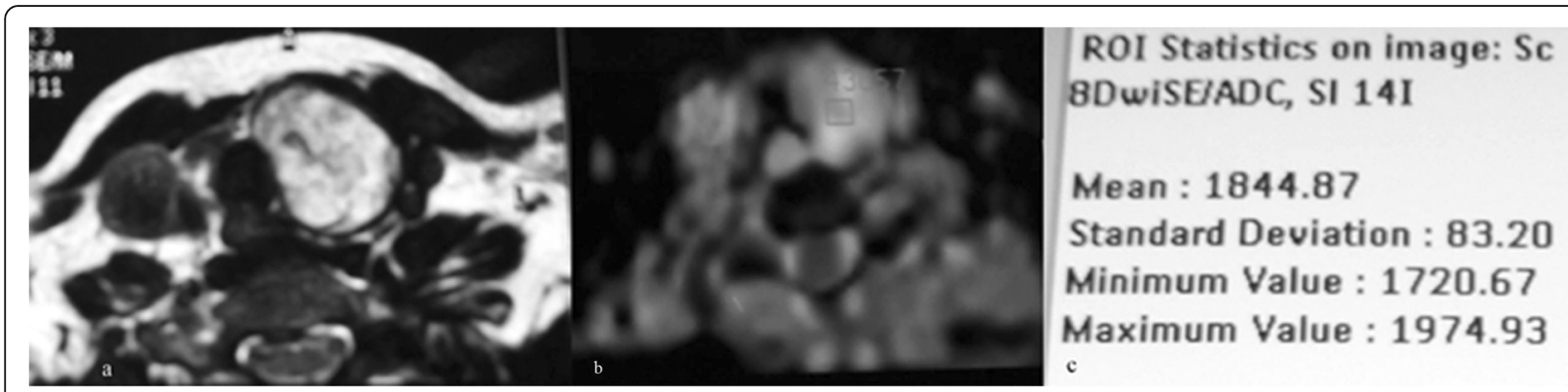

Fig. 1 T2 image (a) and ADC image and value (b, c) for a left lobe thyroid nodule; the mean ADC value was about $1.8 \times 10^{-3}$. Pathology of this nodule was a follicular adenoma 


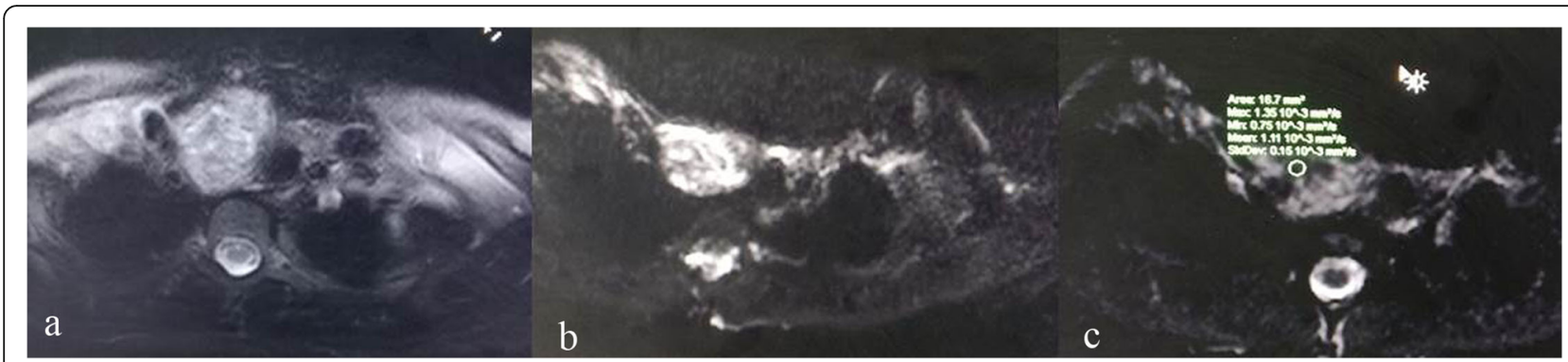

Fig. 2 T2 fat sat image (a), DWI (b), and ADC value $(\mathbf{c})$ for a right lobe thyroid nodule, the mean ADC value was $1.1 \times 10^{-3}$. Pathology of this nodule was a follicular carcinoma in a 62-year-old female

In our study, there was a significant difference between the mean ADC value of benign and malignant nodules $(P$ value $<0.0001)$, the mean ADC of the malignant thyroid nodules (15 nodules) was $\left(0.71 \pm 0.15 \times 10^{-3} \mathrm{~mm}^{2} / \mathrm{s}\right)$ while that of the benign thyroid nodules (58 nodules) was (1.7 \pm $\left.0.12 \times 10^{-3} \mathrm{~mm}^{2} / \mathrm{s}\right)$. This was in concordance with the study of El-Hariri et al. [21] who studied 46 patients with 56 thyroid nodules. The mean ADC of the benign thyroid nodules in their results was $1.85 \pm 0.24 \times 10^{-3} \mathrm{~mm}^{2} / \mathrm{s}$, while the mean ADC of the malignant thyroid nodules was $0.89 \pm 0.27 \times 10^{-3} \mathrm{~mm}^{2} / \mathrm{s}$.

The $A \bar{D} C$ values of malignant thyroid nodules were significantly lower than the ADC values of benign thyroid nodules $(P$ value $<0.0001)$. A recent study of Elshafey et al. [22] also reported high ADC values (1.78 \pm $\left.0.21 \times 10^{-3} \mathrm{~mm}^{2} / \mathrm{s}\right)$ for benign nodules and lower $\mathrm{AD} \overline{\mathrm{C}}$ values $\left(0.59 \pm 0.24 \times 10^{-3} \mathrm{~mm}^{2} / \mathrm{s}\right)$ for malignant nodules, and these were statistically significant $(P$ value $<0.0001)$.

Using the pathology results as a standard reference, area under ROC curve was found to be $98 \%$ for an ADC cutoff value of $0.92 \times 10^{-3} \mathrm{~mm}^{2} / \mathrm{s}$ that corresponded to an acquisition with $b$ value of $400 \mathrm{~s} / \mathrm{mm}^{2}$ with a sensitivity of $97.5 \%$, a specificity of $94.4 \%$, and an accuracy of $99.2 \%$. This cutoff value was conceded with that of Abdel Razek et al. [23], who determined that the ADC value of $0.98 \times 10^{-3} \mathrm{~mm}^{2} / \mathrm{s}$ was the cutoff value differentiating between benign and malignant thyroid nodules with a sensitivity of $97.5 \%$, a specificity of $91.7 \%$, and an accuracy of $98.9 \%$. In the study of Elshafey et al., the reported cutoff value was $0.8 \times 10^{-3} \mathrm{~mm}^{2} / \mathrm{s}$, and this was attributed to the highly cellular adenomatous tissue that shows slight low ADC. Shi et al. found that when the $b$ factor was $500 \mathrm{~s} / \mathrm{mm}^{2}$, an ADC value of $1.704 \times$ $10^{-3} \mathrm{~mm}^{2} / \mathrm{s}$ can be threshold differentiating malignant from benign nodules, with $92 \%$ sensitivity, $88 \%$ specificity, and $87 \%$ accuracy. He clarified that the higher cell density and more severe desmoplastic response were the causes of the lower ADC value of thyroid cancer. A higher cutoff ADC value $\left(2.17 \times 10^{-3} \mathrm{~mm}^{2} / \mathrm{s}\right)$ was determined by $\mathrm{Wu}$ et al. [15] with sensitivity and specificity of 76.5 and $100 \%$, respectively.

The ADC values of benign thyroid nodule may vary according to the complex composition within the nodule (colloid, tiny necrosis and cystic change, hemorrhage, fibrosis, and calcium). ADC values were highest in thyroid cysts since it contained colloid material made of serous or concentrated thyroglobulin [15].

In our study, and using pathological results, we could not depend on the ADC value in differentiating between different pathological subtypes of thyroid nodules. $P$ value ranged from 0.054 to 0.062 between different pathological subtypes. Adenomatous nodule and follicular adenoma showed ADC values of 1.31-1.92 $\times 10^{-3}$ and $1.23-2 \times 10^{-3}$, respectively. For malignant nodules, papillary and follicular carcinomas showed ADC values of $0.72-1.32 \times 10^{-3}$ and $0.61-1.24 \times 10^{-3}$, respectively.

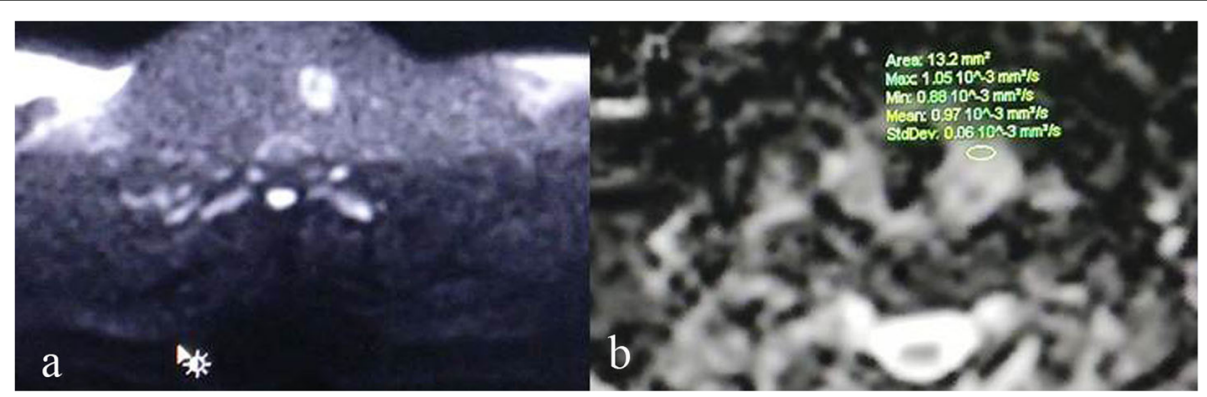

Fig. $3 \mathrm{DWI}$ (a) and ADC value (b) for a left lobe thyroid nodule, the mean ADC value was $0.9 \times 10^{-3}$. Pathology of this nodule was a papillary carcinoma in a 55-year-old male 
Table 3 ADC values of different subtypes of benign and malignant nodules

\begin{tabular}{llll}
\hline Type & No. & ADC range $\left(\mathrm{mm}^{2} / \mathrm{s}\right)$ & ADC mean $\left(\mathrm{mm}^{2} / \mathrm{s}\right)$ \\
\hline Benign & 58 & & \\
Adenomatoius nodule & 37 & $1.31-1.92 \times 10^{-3}$ & $1.8 \times 10^{-3}$ \\
Follicular adenoma & 12 & $1.23-2 \times 10^{-3}$ & $1.7 \times 10^{-3}$ \\
Cysts & 9 & $1.14-2.4 \times 10^{-3}$ & $2 \times 10^{-3}$ \\
Malignant & 15 & & \\
Papillary & 11 & $0.72-1.32 \times 10^{-3}$ & $0.7 \times 10^{-3}$ \\
Follicular & 4 & $0.61-1.24 \times 10^{-3}$ & $0.6 \times 10^{-3}$ \\
\hline
\end{tabular}

This was in agreement with Abdel Razek et al. who found that there were insignificant differences in the ADC values of the various malignant nodules, with $P=464$. Also. in a study done by Schueller-Weidekamm et al., [24] they studied 25 patients with thyroid nodules and stated that there was no statistically significant difference in the ADC values between different pathological subtypes of malignant nodules $(P$ 0.05). These results can be explained by the fact that it is not possible to differentiate the various thyroid gland carcinomas by their specific cell attenuation.

It was suggested that the ADC values of benign thyroid nodule may vary according to the complex composition within the nodule (colloid, tiny necrosis and cystic change, hemorrhage, fibrosis, and calcium) [15], we did not find that much helpful in differentiating between subtypes of benign thyroid nodules. In our study, ADC values were highest in thyroid cysts since it contained colloid cyst made of serous or concentrated thyroglobulin.

Although calcification may lead to a decrease of ADC values in papillary thyroid carcinoma, we also did not find this helpful in differentiating between it and follicular carcinoma.

There are still some limitations in this study. First, the relatively small number $(20.5 \%)$ of the malignant nodules somehow limits the statistical power. Second, small thyroid nodules less than $10 \mathrm{~mm}$ were not included. Improvement in the software of diffusion-weighted MR imaging will help in the detection of smaller lesions in future studies.

\section{Conclusion}

Diffusion MRI including ADC values are helpful in differentiation between benign and malignant thyroid nodules but not helpful in differentiating between different subtypes of benign and malignant nodules.

\section{Abbreviations}

MRI : Magnetic resonance imaging; ADC: Apparent diffusion coefficient; FNAB: Fine needle aspiration biopsy; STIR: Short tau inversion recovery; ROI: Region of interest; ROC: Receiver operating characteristics

\section{Acknowledgements}

We gratefully acknowledge the hard work, efficiency, and devotion of our imaging technicians, which made this work possible.

\section{Authors' contributions}

All authors have read and approved the current manuscript. EA did the design of the study, data collection, MRI image interpretation, and manuscript drafting. EAh did MRI image interpretation, manuscript writing, statistical analysis, and sequence alignment. OA and AA did patient referral, manuscript editing, and sequence alignment. All authors read and approved the final manuscript

Funding

No sources of funding

\section{Availability of data and materials}

The datasets used and/or analyzed during the current study are available from the corresponding author on reasonable request.

Ethics approval and consent to participate

This study was approved by the Research Ethics Committee of the Faculty of Medicine at Minia University in Egypt on June 2019 (reference number is not applicable). All patients included in this study gave written informed consent to participate in this research.

\section{Consent for publication}

All patients included in this research gave written informed consent to publish the data contained within this study

\section{Competing interests}

The authors declare that they have no competing interests.

\section{Author details}

${ }^{1}$ Department of Radiology, Faculty of Medicine, Minia University, Minia, Egypt. ${ }^{2}$ Department of Surgery, Faculty of Medicine, Minia University, Minia, Egypt.

Received: 27 June 2019 Accepted: 18 December 2019

Published online: 07 January 2020

\section{References}

1. Al Mamun A, Alam Z, Haque R, Hasan DM (2014) Study of pathological variations of solitary thyroid nodule. GJMR 14:9-16

2. Mohamed A, Shokrya T, Hassanb Ahmed A, Bazb Ahmed A, Owis S, Mohamed A, Zedan H (2018) Role of diffusion weighted magnetic resonance imaging in differentiation of benign and malignant thyroid nodules. Egypt J Radiol Nuclear Med 49:1014-1021

3. Dilli A, Ayaz UY, Cakir E, Cakal E, Gultekin SS, Hekimoglu B (2012) The efficacy of apparent diffusion coefficient value calculation in differentiation between malignant and benign thyroid nodules. Clin Imaging 36:316-322

4. Solbiati L, Osti V, Cova L, Tonolini M (2001) Ultrasound of thyroid, parathyroid glands and neck lymph nodes. Eur Radiol 11:2411-2424

5. Frates MC, Benson CB, Charboneau JW, Cibas ES, Clark OH, Coleman BG (2005) Management of thyroid nodules detected at US: Society of Radiologists in Ultrasound consensus conference statement. Radiology 237:794-800

6. Gritzmann N, Koischwitz D, Retterbacher T (2000) Sonography of the thyroid and parathyroid glands. Radiol Clin North Am 38:1131-1145

7. Papini E, Guglielmi R, Bianchini A, Crescenzi A, Taccogna S, Nardi F (2002) Risk of malignancy in nonpalpable thyroid nodules: predictive value of ultrasound and color-Doppler features. J Clin Endocrinol Metab 87:1941-1946

8. Price DC (1993) Radiologic evaluation of the thyroid and parathyroid. Radiol Clin North Am 31:991-1015

9. Weber A, Randolph G, Aksoy F (2000) The thyroid and parathyroid glands: $\mathrm{CT}$ and MR imaging and correlation with pathology and clinical findings. Radiol Clin North Am 38:1105-1129

10. Sahin M, Guvener N, Ozer F (2005) Thyroid cancer in hyperthyroidism: incidence rate and value of ultrasound-guided fine-needle aspiration biopsy in this patient group. J Endocrinol Invest 28:815-818

11. Yousem D (1996) Parathyroid and thyroid imaging. Neuroimaging Clin N Am 6:435-459

12. Grant CS, Hay ID, Gough IR, McCarthy PM, Goellner JR (1989) Long-term follow-up of patients with benign thyroid fine-needle aspiration cytologic diagnoses. Surgery 106:980-986 
13. Hamming JF, Goslings BM, Van Steenis GJ, Van Ravenswaay CH, Hermans J, Van de Velde CJH (1990) The value of fine-needle aspiration biopsy in patients with nodular thyroid disease divided into groups of suspicion of malignant neoplasms on clinical grounds. Arch Intern Med 150:113-116

14. Mazzaferri EL (1993) Management of a solitary thyroid nodule. N Engl J Med 328:553-559

15. Wu Y, Yue X, Shen W, Du Y, Yuan Y, Tao X, Tang CY (2013) Diagnostic value of diffusion-weighted MR imaging in thyroid disease: application in differentiating benign from malignant disease. BMC Med Imaging 13:23

16. Abdel Razek AAK (2018) Routine and advanced diffusion imaging modules of the salivary glands. Neuroimag Clin 28:2454-2254

17. Eida S, Sumi M, Sakihama N, Takahashi H, Nakamura T (2007) Apparent diffusion coefficient mapping of salivary gland tumors: prediction of the benignancy and malignancy. AJNR Am J Neuroradiol 28:116-121

18. King CH, Higa AT, Culjat MO, Han SH, Bisley JW (2007) A pneumatic haptic feedback actuator array for robotic surgery or simulation. Stud Health Technol Inform 125:217-222

19. Noda Y, Kanematsu M, Goshima S et al (2015) MRI of the thyroid for differential diagnosis of benign thyroid nodules and papillary carcinomas. AJR 204:332-335

20. Giuffrida D, Prestifilippo A, Scarfia A, Martino D, Marchisotta S (2012) New treatment in advanced thyroid cancer. J Oncol 22:1-10

21. El-Hariri M, Gouhar G, Said N, Riad M (2012) Role of diffusion weighted imaging with ADC mapping and in vivo 1H-MR spectroscopy in thyroid nodules. Egypt J Radiol Nucl Med 43:183-192

22. Elshafey R, Elattar A, Melees M, Esheba N (2014) Role of quantitative diffusion-weighted MRI and 1H MR spectroscopy in distinguishing between benign and malignant thyroid nodules. Egypt J Radiol Nucl Med 45:89-96

23. Razek AA, Sadek AG, Kombar OR, Elmahdy TE, Nada N (2008) Role of apparent diffusion coefficient values in differentiation between malignant and benign solitary thyroid nodules. AJNR Am J Neuroradiol 29:563-568

24. Schueller-Weidekamm C, Kaserer K, Schueller G, Scheuba C, Ringl H, Weber M, Czerny C, Herneth AM (2009) Can quantitative diffusion-weighted MR imaging differentiate benign and malignant cold thyroid nodules? Initial results in 25 patients. AJNR Am J Neuroradiol 30:417-422

\section{Publisher's Note}

Springer Nature remains neutral with regard to jurisdictional claims in published maps and institutional affiliations.

\section{Submit your manuscript to a SpringerOpen ${ }^{\circ}$ journal and benefit from:}

- Convenient online submission

- Rigorous peer review

- Open access: articles freely available online

- High visibility within the field

- Retaining the copyright to your article

Submit your next manuscript at $\boldsymbol{\nabla}$ springeropen.com 